\section{Antimicrobial activity of selected natural products against Gram-positive, Gram-negative and Acid-fast bacterial pathogens}

\author{
Niket Yadav, ${ }^{1}$ Ekta Yadav, ${ }^{2}$ \\ Jagjit S. Yadav ${ }^{1}$ \\ 1Department of Environmental Health \\ and 2Department of Molecular and \\ Cellular Physiology, University of Cincinnati \\ College of Medicine, Cincinnati, OH, USA
}

\section{Abstract}

Recurring epidemics of drug resistant bacterial diseases such as those caused by mycobacteria (tuberculosis and non-tuberculous infections), staphylococci (methicillin-resistant Staphylococcus aureus or MRSA infections) and various Gram-negative enterobacteria (enterobacterial infections) have reinforced the need to search for alternative antimicrobials. In this context, we investigated the antibacterial potential of nine different natural products and compared them with the antibiotic controls, using three test bacterial species, representing the Gram-negative (Escherichia coli), Gram-positive (Staphylococcus epidermidis), and Acid-fast (Mycobacterium smegmatis) pathogen groups. Six of the nine products showed detectable but variable zones of inhibition $\left(\mathrm{mm}^{2}\right)$. The antibacterial activity ( $\mathrm{mm}^{2}$ per $100 \mathrm{mg}$ ) of the extracts from the four solid natural products was in the following order for all three pathogen groups: Mint (Mentha arvensis) leaf extract, 264-930>Mushroom (Agaricus bisporus) cap extract, 112-241 $>$ Turmeric (Curcuma longa) root extract, 4-10>Ginger (Zingiber officinale) root extract, 3-9. For the liquid products, the activity measured on 100 $\mu \mathrm{L}$ aliquots was in the following order: Eucalyptus (Eucalyptus globules) oil, 2641044>Mustard (Brassica campestris L. var. brown sarson) oil, 45-96. Taken together, these results indicated the highest activity in Mint extract and Eucalyptus oil against all three test organisms. However, the individual test strains showed the following variable order of susceptibility: Mint extract (M. smegmatis $>E$. coli $>S$. epidermidis); Eucalyptus oil (M. smegmatis $>$ S. epidermidis $>$ E. coli). Based on these results it can be concluded that Mint leaves and Eucalyptus oil have an unusually broad spectrum activity and may, therefore, be promising sources of new broad spectrum antimicrobials.

\section{Introduction}

Since the discovery of the first antibiotic, penicillin, in 1929, antibiotics have revolutionized modern medicine. However, in the past few decades, there have been increasing global incidences of microbial infections showing resistance to the existing antimicrobial agents.1,2 The ensuing challenges in the treatment of infectious diseases caused by the drug resistant and emerging pathogens have intensified in the $21^{\text {st }}$ century. 3,4 This phenomenon is of great concern and has global public health significance. Our ability to effectively combat resistant and emerging pathogenic strains is dependent on the development of novel antimicrobials. This emphasizes the continuing need for discovering new antimicrobials. In this context, as a part of the latest Public Health Action Plan To Combat Antimicrobial Resistance, an Interagency Task Force on Antimicrobial Resistance (co-chaired by the United States federal agencies CDC, FDA, NIH) has presented a proposal to support development of novel broad spectrum antimicrobials (http://www.cdc. gov/drugresistance/pdf/2010/InteragencyAction-Plan-PreClearance-03-2011.pdf).

For centuries, ancient human civilizations and peoples of various continents have been using natural plant-derived products to heal various ailments, including infections.5-10 In certain Asian and African countries such as India, use of medicinal plants or their derived products still forms a significant part of current medical treatment and practice following traditional medicinal systems, such as the Ayurveda in the Indian subcontinent. ${ }^{11}$ An estimated $80 \%$ of the population in developed nations use medications that are based on components originally derived from medicinal plants. ${ }^{12} \mathrm{~A}$ number of traditional medicinal plants have been used for their multifaceted therapeutic properties, including anti-infective effects. ${ }^{13-19}$ Therefore, one viable alternative could be to identify specific promising natural products that could serve as sources of new broad spectrum antimicrobials. Such antimicrobials could be harnessed to design new antibiotics, 20,21 bioactive supplements to antibiotics, 22 or for use as disinfectants or preservatives for preventing the spread of resistant microbial strains.

Globally, the bacterial pathogens are responsible for the majority of the infectious diseases such as tuberculosis, enteric diseases, and septic infections. The causative bacterial pathogens for these diseases fall into one or more of the three groups based on their cell wall staining characteristics (http//visualsunlimited.photoshelter.com/image/I0000yfHHFqEytaI): Gram-positive, Gram-negative, and Acid-fast bacteria. Specific antibiotics are effective
Correspondence: Jagjit S. Yadav, Microbial Pathogenesis and Toxicogenomics Laboratory, Department of Environmental Health, University of Cincinnati College of Medicine, 3223 Eden Avenue, Kettering Complex, Cincinnati, Ohio 45267-0056, USA.

Tel. +1.513.558.4806 - Fax: +1.513.558.4397.

E-mail: jagjit.yadav@uc.edu

Key words: antibacterial activity, natural products, mycobacterium, staphylococcus, E. coli.

Contributions: NY and EY participated in conceptualization and design of study, performed the experiments, analyzed and interpreted the data, and prepared manuscript; JSY was involved in conceptualization and supervision of experiments, data analysis and interpretation, and writing. $\mathrm{NY}$ and $\mathrm{EY}$ contributed equally to the study.

Conflict of interests: the authors declare no conflict of interests.

Acknowledgments: thanks are due to Shalini Bhatnagar for initial training assistance.

Received for publication: 14 April 2012.

Revision received: 3 June 2012.

Accepted for publication: 8 June 2012

This work is licensed under a Creative Commons Attribution NonCommercial 3.0 License (CC BYNC 3.0).

(C) Copyright N. Yadav et al., 2012

Licensee PAGEPress, Italy

Alternative Medicine Studies 2012; 2:e13

doi:10.4081/ams.2012.e13

against specific bacterial groups with some exceptions that are designed to possess broad spectrum antimicrobial activity. Novel broad spectrum antimicrobials could be the choice for the $21^{\text {st }}$ century to combat emerging strains and mixed infections. In light of this, the current study was aimed at investigating the potential of selected natural products as sources of such broad spectrum antimicrobials. In this study, the selection of the test natural products was motivated by their reported historical use for various ailments in traditional Indian medicine (Table 1).

Extracts from nine natural products were tested against the three bacterial types (Grampositive, Gram-negative, and Acid-fast) using model test species representing the three categories of pathogenic bacteria commonly associated with infectious diseases. To our knowledge, such a broad spectrum antimicrobial activity of these selected products, particularly against mycobacteria, has not been reported. 


\section{Materials and Methods}

\section{Natural products and their ethyl acetate extracts}

A total of 9 natural products comprising 8 plant-derived products and one dairy product Indian yogurt were investigated. The scientific and common names of the products along with their traditional medicinal use are listed in Table 1. The plant-derived natural products were obtained from the local Indian American (Bombay Grocers, Cincinnati, OH, USA) and International (Jungle Jims, Cincinnati, $\mathrm{OH}$, USA) grocery stores and included four products in liquid form (oil or aqueous extract/juice) and four as solids; the latter were converted into liquid organic extracts. All products except the mushroom caps and the Indian yogurt were imported products from India. Among the oils used in this study, Eucalyptus oil is an essential oil obtained by steam distillation of leaves and twigs of the source plant species. Mustard oil and Neem oil are fixed oils obtained by expression of the crushed seeds of the source plant species followed by clarification. The following amounts (range 2.5-200 g) of the individual natural products in solid form, decided depending on the bulkiness and/or dry versus wet status of the product, were used for extraction: Ginger root powder $50 \mathrm{~g}$ dry weight $(\mathrm{dw})$, Turmeric root powder $50 \mathrm{~g}(\mathrm{dw})$, dried Mint leaves $2.5 \mathrm{~g}$ (dw), fresh Mushroom caps 200 g wet weight. Mint leaves and Mushroom caps were shredded using a mechanical grinder/mixer (The Black and Decker Corporation, Towson, Maryland, USA) before extraction. Ethyl acetate was used as the extraction solvent considering its known broad potential for recovering organic components from complex matrices such as the plant natural products. Each product was extracted with an appropriate volume of ethyl acetate sufficient to submerge the product and the process was repeated three times. The triplicate extracts were separated by filtration using Whatman paper 40 , and dried under low vacuum in a rotary evaporator until completely dry. The dried residue was recovered using a minimum amount of the same solvent, transferred to a $2 \mathrm{~mL}$ glass vial and evaporated under nitrogen gas to complete drying. The dried extract residue was weighed to estimate the recovery and re-dissolved in a defined amount $(1 \mathrm{~mL})$ of the same solvent. The final concentration in the suspension was calculated (Table 2). This mother suspension was filter sterilized using $0.45 \mu \mathrm{m}$ sterile Nalgene syringe filter units (Fisher Scientific, Pittsburgh, PA 15275, USA) and used as the test suspension in the antibacterial activity assays. The original preparations (4 oz size each) of the liquid natural products, namely Neem oil, Mustard oil, Eucalyptus oil, Basil juice and Indian yogurt-liquid part (homemade) were used directly in the assay without further concentration or dilution.

\section{Bacterial strains and culture conditions}

The test bacterial species/strains, namely $E$. coli DH5 (ATCC 53868), Staphylococcus epidermidis Fussel (ATCC 14990), and Mycobacterium smegmatis mc(2)155 (ATCC 700084) were used as surrogates of the three bacterial staining groups: Gram-negative, Gram-positive, and Acid-fast bacteria, respectively. All strains were obtained from American Type Culture Collection (ATCC), Manassas, VA, USA. The strains were routinely maintained by subculturing on agar media plates using trypticase soy agar (BD Difco ${ }^{\mathrm{TM}}$, Becton Dickinson \& Co., Spaks MD, USA) for $E$. coli and $S$. epidermidis and Middlebrook 7H10 agar with OADC enrichment (BD Difco ${ }^{\mathrm{TM}}$, Becton \& Dickinson Co., Spaks MD, USA) for M. smegmatis. Master stocks for long-term frozen storage $\left(-80^{\circ} \mathrm{C}\right)$ were prepared using the respective broth media supplemented with glycerol (15\% final concentration).

Table 1. List of natural products used in the study.

\begin{tabular}{|c|c|c|c|c|c|}
\hline $\begin{array}{l}\text { Product name } \\
\text { (English) }\end{array}$ & $\begin{array}{l}\text { Common name } \\
\text { (Hindi) }\end{array}$ & Botanical name & Family & $\begin{array}{l}\text { Plant } \\
\text { part/form used }\end{array}$ & Medicinal applications \\
\hline Ginger & Adrak & Zingiber officinale & Zingiberaceae & Root & Treat diarrhea, colic infections, nausea, arthritis \\
\hline Turmeric & Haldi & Curcuma longa & Zingiberaceae & Root & $\begin{array}{l}\text { Indigestion, ulcerative colitis, osteoarthritis, } \\
\text { atherosclerosis in some animals }\end{array}$ \\
\hline Mint & Pudina & Mentha arvensis & Lamiaceae & Leaf & $\begin{array}{l}\text { Treat stomach ache and other digestive disorders, } \\
\text { chest pain, teeth whitening, diuretic }\end{array}$ \\
\hline Mushroom & Mushroom & Agaricus bisporus & Agaricaceae & Cap of mushroom & $\begin{array}{l}\text { Cholesterol regulation, some species possess } \\
\text { antifungal, antibacterial, antiviral, or antimicrobial } \\
\text { properties as a defense mechanism }\end{array}$ \\
\hline Neem oil & Neem & Azadirachta indica & Meliaceae & Seed & $\begin{array}{l}\text { Treat various skin disorders (i.e. leprosy, skin ulcers, } \\
\text { chicken pox, acne), pest repellant }\end{array}$ \\
\hline Mustard oil & Sarson & $\begin{array}{l}\text { Brassica } \\
\text { campestris L. var. } \\
\text { brown sarson }\end{array}$ & Brassicaceae & Seed & $\begin{array}{l}\text { Treat skin disorders, Internal congestion, } \\
\text { sore-throat, pneumonia }\end{array}$ \\
\hline Eucalyptus oil & Nilgiri & Eucalyptus globules & Myrtaceae & Leaf/twig & $\begin{array}{l}\text { Treat diabetes, coughs and the common cold, } \\
\text { congestion, bronchitis, bad breath; can be used } \\
\text { to revive someone who has fainted; } \\
\text { insect repellant }\end{array}$ \\
\hline Basil juice & Tulsi & Ocimum sanctum & Lamiaceae & Leaf & $\begin{array}{l}\text { Used to clear the bronchial tube, treatment for } \\
\text { fever and the common cold, coughs, sore throat, } \\
\text { respiratory disorder, kidney stones, heart } \\
\text { disorder, diarrhea, stress, mouth infections, skin } \\
\text { disorders, teeth disorders, insect bites, } \\
\text { headaches, eye disorders }\end{array}$ \\
\hline Indian yogurt & Dahi & - & - & $\begin{array}{l}\text { Liquid part } \\
\text { of the yogurt }\end{array}$ & $\begin{array}{l}\text { Strengthens immune system and digestive } \\
\text { health, adequate consumption can minimize } \\
\text { bladder and vaginal infections in women, remedy } \\
\text { for yeast infections }\end{array}$ \\
\hline
\end{tabular}




\section{Preparation of inocula}

The three test strains were freshly cultured in their respective broth media at $37^{\circ} \mathrm{C}$ using 200 rpm until mid-log phase to obtain 120 reading on the Klett-Summerson photometer. A working stock of the cell suspension $\left(1 \times 10^{7}\right.$ colony forming units/mL) was prepared by centrifugation $(10,000 \times \mathrm{g}$ for $15 \mathrm{~min})$ and resuspension in $1 \times$ PBS $(0.01 \mathrm{M})$, pH 7.4 (Sigma, St. Louis, M0, USA). The cells were monodispersed by repeated passaging through 26 Gauge BD syringe needle (Becton Dickinson \& Co., Franklin Lakes, NJ, USA), and the cell suspensions stored at $4^{\circ} \mathrm{C}$ till use. The cell viability of the working stock was verified based on standard plate count method using the respective agar media.

\section{Antibacterial activity assay}

Antibacterial activity of the products/extracts was measured in terms of zone of inhibition of growth in an agar well diffusion assay using each of the three test bacterial species: $E$. coli, $S$. epidermidis, and $M$. smegmatis. A negative control (saline for the liquids and ethyl acetate for the extracts) and a positive control (an appropriate antibiotic) were used for comparison. The antibiotics effective against the test species were obtained from Sigma and used as the following working stocks: amikacin (5 $\mu \mathrm{g} / \mathrm{mL}$ ) for $E$. coli, cefoxitin $(5 \mu \mathrm{g} / \mathrm{mL})$ for $S$. epidermidis, and doxycycline ( $1 \mu \mathrm{g} / \mathrm{mL})$ for $M$. smegmatis. Agar plates for the assay were prepared using the appropriate agar medium, namely trypticase soy agar for $E$. coli and $S$. epidermidis; Middlebrook 7H10 agar (MBA) for M. smegmatis, reconstituted according to the manufacturer's instructions. A defined amount of the cell suspension $\left(100 \mu \mathrm{L}\right.$ of the $1 \times 10^{7}$ $\mathrm{CFU} / \mathrm{mL}$ working stock) of $E$. coli, $S$. epidermidis, or $M$. smegmatis was spread on the assay plates using sterile cell spreaders. Uniform defined size wells $(8 \mathrm{~mm})$ were made in the agar plates. An aliquot $(100 \mu \mathrm{L})$ of the extract or liquid product or the antibiotic stock solution was placed in the test well, filling it to two-thirds of its capacity. The actual mg amounts per $100 \mu \mathrm{L}$ volume of the natural product extracts are shown in Table 2. The final antibiotic amounts used in the positive control wells were amikacin $0.5 \mu \mathrm{g}(E$. coli $)$, cefoxitin $0.5 \mu \mathrm{g}$ (S. epidermidis) and doxycycline $0.1 \mu \mathrm{g}$ (M. smegmatis). The negative control used was either ethyl acetate (assay plates for solid product extracts) or saline (assay plates for liquid products). The plates were incubated at $37^{\circ} \mathrm{C}$ for $24 \mathrm{~h}$ (or $48 \mathrm{~h}$ for M. smegmatis). The assay was repeated three times for each bacterial species using all 9 products/ extracts and the two controls.

\section{Calculations}

For calculating the net area of the zone of clearance, the following measurements were taken: well diameter in millimeter (mm); total diameter of the zone of clearance (including the well) in $\mathrm{mm}$. These diameters were converted first into radii and then into areas using the formula: area $=3.14 \times \mathrm{r}^{2}$ where $\mathrm{r}$ is the radius of the zone ( $\mathrm{r}=$ half of the diameter). The net area of the zone of clearance was calculated by subtracting the area of the well from the total area.

\section{Results and Discussion}

The antimicrobial activity measured as area of zone of inhibition varied with the natural product and with the test bacterial species (Figure 1; Table 2). The results showed that Eucalyptus and Mint can inhibit species of all three bacterial groups (Gram-positive, Gram-negative, and Acid-fast). The test bacterial types showed the following order of susceptibility to Eucalyptus oil (M. smegmatis $>S$. epidermidis $>E$. coli); the order differed for the Mint extract (M. smegma- tis $>$ E. coli $>S$. epidermidis). This collectively implied that these products possess a broad spectrum antimicrobial property. A similar phenomenon was observed for Mushroom, Turmeric, and Ginger, albeit to a lower extent. Mustard oil, however, showed differential antibacterial activity, with no detectable clearance zone against $M$. smegmatis. Basil juice, Neem oil and Yogurt liquid showed no detectable activity in the tested preparations (Figure 2).

Quantitatively, the order of the activity of the products, assessed on equal volumes of the test liquid/suspension (100 $\mu \mathrm{L}$ each), was as follows: Eucalyptus oil<or $>$ Mint leaf extract $>$ Mustard seed oil $>$ Ginger root extract=Turmeric root extract=Mushroom cap extract (Figure 1). However, when compared in terms of unit mass of the test extracts (per mg of the extract/mother suspension), the four solid product extracts showed the activity against all three test strains in the following order: Mint leaf extract> Mushroom cap extract>Turmeric root extract> Ginger root extract (Table 2). Collectively, these results showed that Eucalyptus oil and Mint extract possess the highest activities (Figure 1; Table 2) against all three test strains, albeit to a varying extent.

The assay also allowed quantitative comparison of the antibacterial activity of some of the crude extracts (extracts with known mg concentrations) with those of the respective pure test antibiotic controls (Table 2; Figure 1). For instance, Mint extract (10 mg) had approximately 3.5 -fold activity against $M$. smegmatis as compared to $100 \mathrm{ng}$ of doxycycline, 2.7-fold activity against $S$. epidermidis compared to 500 ng cefoxitin and 5.2-fold activity against $E$. coli compared to $500 \mathrm{ng}$ of amikacin. The other solid products at their test concentrations showed relatively lower activity than the antibiotic controls.

There have been past reports in the literature documenting the medicinal properties of the tested products or their source plants, including antimicrobial effects. For example, Eucalyptus is used by traditional medical practitioners in

Table 2. Concentrations of the natural product extracts (mother suspensions) and their relative antibacterial activity per unit mass.

\begin{tabular}{|c|c|c|c|c|c|c|c|c|c|}
\hline \multirow{3}{*}{$\begin{array}{l}\text { Natural product } \\
\text { Name }\end{array}$} & \multirow[b]{3}{*}{$\begin{array}{l}\text { Original } \\
\text { weight } \\
\text { used for } \\
\text { extraction } \\
\text { (g) }\end{array}$} & \multirow{2}{*}{\multicolumn{3}{|c|}{$\begin{array}{l}\text { Mother suspension } \\
\text { (Ethyl acetate-extracted fraction) }\end{array}$}} & \multicolumn{5}{|c|}{ Agar well diffusion assay } \\
\hline & & & & & \multicolumn{2}{|c|}{$\begin{array}{l}\text { Test concentration } \\
\text { of the mother } \\
\text { suspension per well }\end{array}$} & \multicolumn{3}{|c|}{$\begin{array}{l}\text { Clearance zone area } \\
\text { per } \mathrm{mg} \text { extract in mother } \\
\text { suspension }\left(\mathrm{mm}^{2}\right)\end{array}$} \\
\hline & & $\begin{array}{l}\text { Dry } \\
\text { weight } \\
\text { of the } \\
\text { extract } \\
\text { (g) }\end{array}$ & $\begin{array}{l}\text { Solvent } \\
\text { volume } \\
\text { used for } \\
\text { resuspension } \\
\text { (mL) }\end{array}$ & $\begin{array}{l}\text { Concentration } \\
(\mathrm{mg} / \mathrm{mL})\end{array}$ & $\begin{array}{l}\text { Volume } \\
\text { ( } \mathrm{LL})\end{array}$ & (mg) & E. coli & S. epidermidis & M. smegmatis \\
\hline Mint leaves (dry) & 2.5 & 0.10 & 1 & 100 & 100 & 10 & 62.5 & 26.4 & 93.0 \\
\hline Ginger root powder & 50 & 1.21 & 1 & 1210 & 100 & 121 & 0.37 & 0.28 & 0.86 \\
\hline Turmeric root powder & 50 & 1.15 & 1 & 1150 & 100 & 115 & 0.44 & 0.49 & 0.97 \\
\hline Mushroom (wet) & 200 & 0.04 & 1 & 40 & 100 & 4 & 11.19 & 12.65 & 24.10 \\
\hline
\end{tabular}


Africa to treat tuberculosis and related respiratory diseases. An inhalational therapy involving Eucalyptus oil vapors is administered for these ailments. However, according to a recent survey, ${ }^{16}$ no laboratory studies on its activity toward the tuberculosis pathogen (Mycobacterium tuberculosis) have been reported. In this context, it is promising that the current study provides laboratory evidence of in vitro antimicrobial activity of Eucalyptus oil against a related model Mycobacterium species. Likewise, other natural products such as Mint, Ginger, Turmeric and Mushroom have been in use in traditional Asian medical practice and have been documented to have a range of therapeutic properties..$^{9,15,17-19}$ Our results provide the scientific basis of the antimicrobial property of these medicinal products and in particular identify the specific broad spectrum antibacterial potential in these products. Lack of considerable antibacterial activity of certain test products such as Neem seed oil and Basil juice in this study may be attributed to the nature or concentration of the specific preparations used. In this context, it has been well documented that the antimicrobial property of plant products depends on the plant part used to obtain the product and the method of extraction. $14,23,24$

The antimicrobial property of the plant products is due to the presence of specific active chemical components. Such specific antimicrobial chemicals are acquired by plants as a self defense mechanism to combat microbial attacks and infections in general. These same plant chemicals could possess antimicrobial activities against human pathogens. This hypothesis may possibly explain the reported broad spectrum activities of the tested natural plant products such as Eucalyptus and Mint toward the three major groups of human pathogens. This study has some limitations. For instance, future efforts may be needed to characterize the toxicity aspects of these products. Certain products may have possible toxic properties in their native form, particularly when used at high concentrations. Nonetheless, such possible adverse side effects of the otherwise promising antimicrobial natural products may be circumvented by identification and use of specific active chemical components. This aspect requires further investigation.

\section{Conclusions}

In conclusion, the tested natural products varied in their antimicrobial activity against the test bacterial agents as compared to antibiotics. In particular, the Eucalyptus oil and Mint extract showed the highest levels of antimicrobial property against all three test bacterial groups. Considering the fact that they showed a broad spectrum antimicrobial activity, these

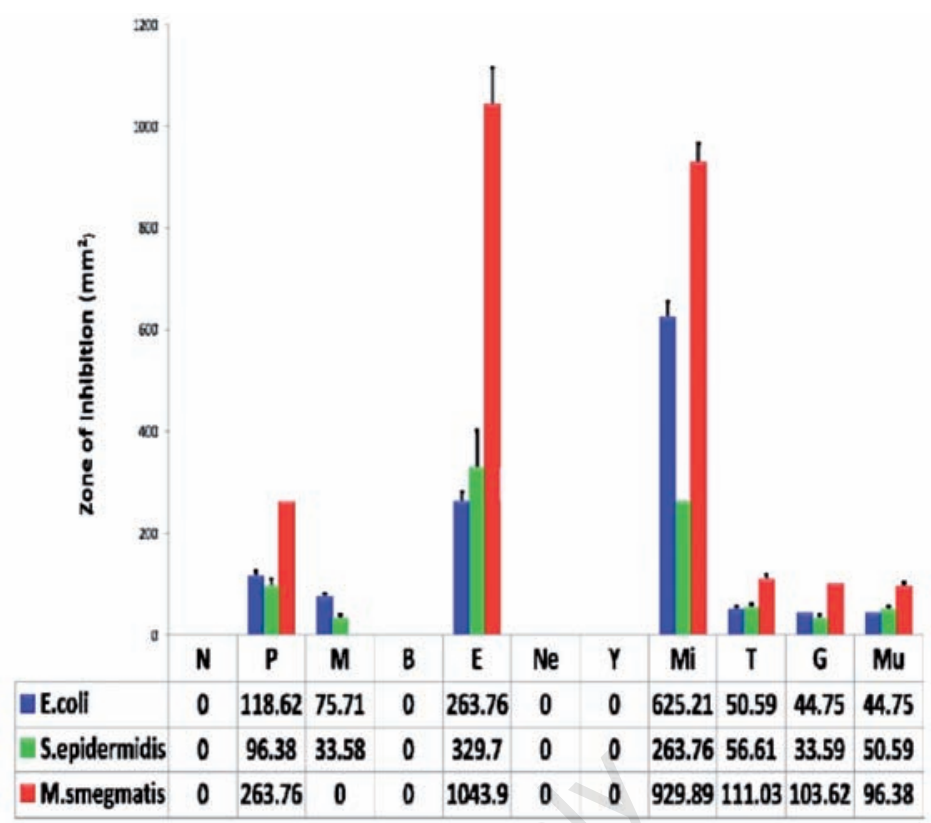

Figure 1. Comparison of the antibacterial activity of various natural products/extracts against. E. coli (blue bar). Staphylococcus epidermidis (green bar). Mycobacterium smegmatis (red bar). The activity was measured as area of zone of clearance $\left(\mathrm{mm}^{2}\right)$ on the agar diffusion assay plate as described under Materials and Methods section. The antibacterial activity was compared using defined amounts of antibiotics as positive control and the vehicle (saline or ethyl acetate) as a negative control. The following antibiotics were used as the respective positive controls: $500 \mathrm{ng}$ amikacin $(E$. coli), $500 \mathrm{ng}$ cefoxitin $(S$. epidermidis), and $100 \mathrm{ng}$ doxycycline (M. smegmatis). The experiment was done in triplicate $(n=3)$. The results are plotted as means \pm standard errors; the corresponding values of the areas of zones of clearance for individual test strains are indicated below the respective products in the graph. N, Negative control (saline or solvent); P, Positive control (antibiotic); E, Eucalyptus oil; B, Basil juice; M, Mustard seed oil; Ne, Neem seed oi; Y, Yogurt liquid; Mi, Mint leaf extract; G, Ginger root extract; T, Turmeric root extract; Mu, Mushroom caps extract.
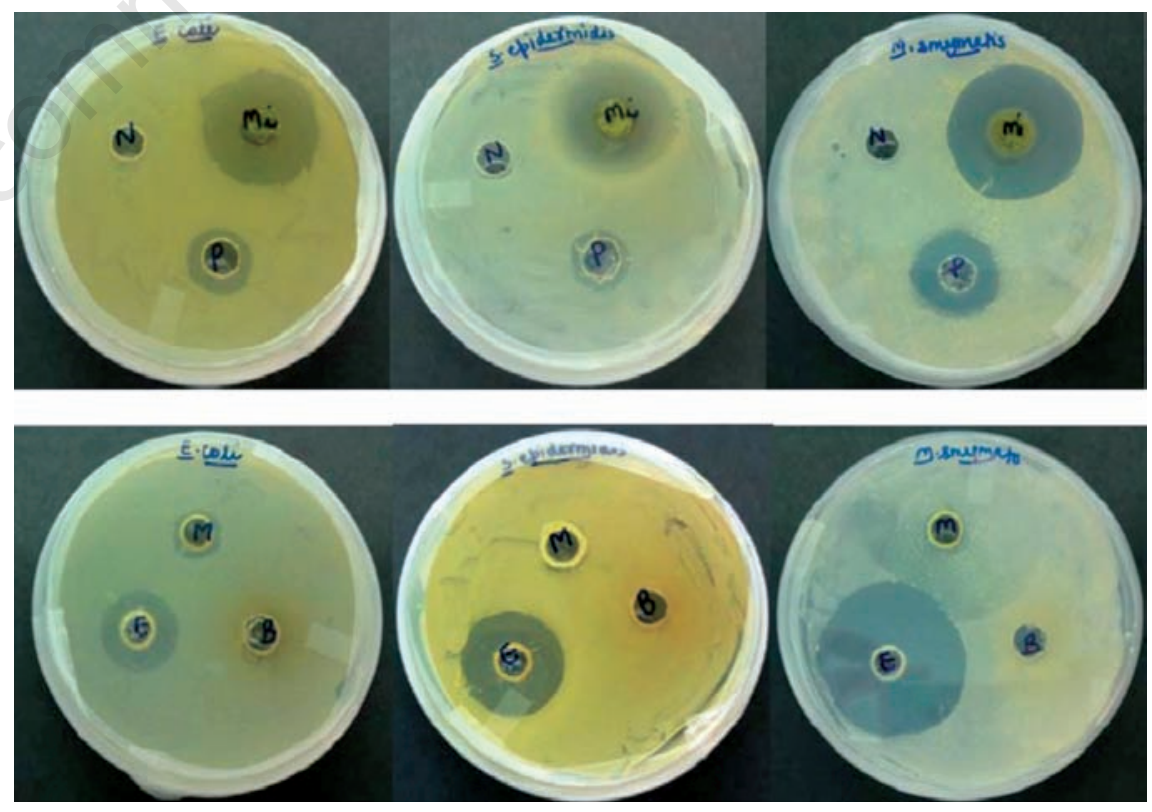

Figure 2. Zone of inhibition of the selected natural extracts toward the test organisms $E$. coli, S. epidermidis, and M. smegmatis as compared to the positive (antibiotic) and negative (solvent) controls. The respective antibiotics used as positive control were amikacin 0.5 $\mathrm{g}$ (E. coli), cefoxitin $0.5 \mu \mathrm{g}$ (S. epidermidis) and doxycycline $0.1 \mu \mathrm{g}$ (M. smegmatis). Ethyl acetate was used as the negative control. One hundred $\mu \mathrm{L}$ of the extract or the control was used per well. Abbreviations: $\mathrm{N}=$ Negative control; $\mathrm{P}=$ Positive control (antibiotic); Mi, Mint leaf extract; E, Eucalyptus oil; B, Basil juice; M,Mustard seed oil. 
products may be expected to possess a broad species-independent mechanism to inhibit a bacterial cell. This implies that these products may find potential applications in providing the antimicrobial leads active against the resistant and polymicrobial infections, or in disinfection or preservative applications in clinical and veterinary practice. Future efforts to identify the specific active chemical components with the determination of safe levels for biological use could lead to the development or design of broad spectrum antimicrobials from these promising natural products.

\section{References}

1. Cohen ML. Epidemiology of drug resistance: implications for a post-antimicrobial era. Science 1992;257:1050-5.

2. Sack RB, Khan EH. Antimicrobial resistance in organisms causing diarrheal disease. Clin Infect Dis 1997;24:S102-5.

3. Westh H, Zinn CS, Rosdahl VT. Sarisa study group: an international multicenter study of antimicrobial consumption and resistance in Staphylococcus aureus isolates from 15 hospitals in 14 countries. Microb Drug Resist 2004;10:169-76.

4. Gottlieb T, Nimmo GR. Antibiotic resistance is an emerging threat to public health: an urgent call to action at the Antimicrobial Resistance Summit 2011. Med J Australia 2011;194:281-3.

5. Cowan MM. Plant products as antimicrobial agents. Clin Microbiol Rev 1999;12: 564-82.
6. Balunas MJ, Kinghorn AD. Drug discovery from medicinal plants. Life Sci 2005;78: 431-41.

7. Barbour EK, Al Sharif M, Sagherian VK, et al. Screening of selected indigenous plants of Lebanon for antimicrobial activity. J Ethnopharmacology 2004;93:1-7.

8. McCutcheon AR, Ellis RM, Hancock REW, Towers GHN. Antibiotic screening of medicinal plants of the British Columbian native peoples. J Ethnopharmacology 1992;37:213-23.

9. Thangapazham RL, Sharma A, Maheshwari RK. Beneficial role of curcumin in skin diseases. Adv Exp Med Biol 2007;595:343-57.

10. Frey FM, Meyers R. Antibacterial activity of traditional medicinal plants used by Haudenosaunee peoples of New York State. BMC Complem Alternative Med 2010;10:1-10

11. Chopra A, Doiphode VV. Ayurvedic medicine: core concept, therapeutic principles, and current relevance. Med Clin North Am 2002;86:75-89.

12. Khond M, Bhosale JD, Arif T, et al. Screening of some selected medicinal plants extracts for in-vitro antimicrobial activity. Middle East J Scientific Res 2009; 4:271-8.

13. Subapriya R, Nagini S. Medicinal properties of neem leaves: a review. Curr Med Chem Anticancer Agents 2005;5:149-6.

14. Biswas K, Chattopadhyay I, Banerjee RK, Bandyopadhyay U. Biological activities and medicinal properties of Neem (Azadirachta indica). Curr Sci 2002;82: 1336-45.
15. Pari L, Tewas D, Eckel J. Role of curcumin in health and disease. Arch Physiol Biochem 2008;114:127-49.

16. Sadlon AE, Lamson DW. Immune-modifying and antimicrobial effects of eucalyptus oil and simple inhalation devices. Altern Med Rev 2010;15:33-47.

17. Lakshmi B, Tilak JC, Adhikri S, et al. Evaluation of antioxidant activity of selected Indian mushrooms. Pharma Biol 2004;42:179-85.

18. Lindequist U, Niedermeyer THJ, Julich W. The pharmacological potentials of mushrooms. Ecam 2005;2:285-99.

19. Butt MS, Sultan MT. Ginger and its health claims: molecular aspects. Crit Rev Fd Sci Nutr 2011;51:383-93.

20. Kumar VP, Chauhan NS, Padh H, Rajani M. Search for antibacterial and antifungal agents from selected Indian medicinal plants. J. Ethnopharmacology 2006;107: 182-8.

21. Arora DS, Kaur GJ. Antibacterial activity of some Indian medicinal plants. J Nat Med 2007;61:313-7.

22. Ejim L, Farha MA, Falconer SB, et al. Combinations of antibiotics and nonantibiotic drugs enhance antimicrobial efficacy. Nature Chem Biol 2011;7:348-50.

23. Ellof JN. Which extractant should be used for the screening and isolation of antimicrobial components from plants? J Ethnopharmacology 1998;60:1-8.

24. Nwachukwu E, Uzoeto HO. Antimicrobial activity of some local mushrooms on pathogenic isolates. J Med Plants Res 2010;4: 2460-5. 